\title{
Left Atrial Appendage Ostial Stenosis in a Patient with Atrial Flutter and Asymmetric Septal Hypertrophy
}

Woohyeun Kim, Won Young Jang, Eun Jin Park, Jah Yeon Choi, Cheol Ung Choi, Hong Euy Lim, Jin Won Kim, Eung Ju Kim, Seung-Woon Rha, Chang Gyu Park, Hong Seog Seo, Dong Joo Oh and Jin Oh Na*

Cardiovascular Center, Korea University Guro Hospital, Korea

Submission: August 28, 2017; Published: August 30, 2017

*Corresponding author: Jin Oh Na, Cardiovascular Center, Korea University Guro Hospital, 148 Gurodong-ro, Guro-gu, Seoul 08308, Korea, Tel: 82-2-2626-3025; Fax: 82-2-863-1109; Email: koolup93@gmail.com

\begin{abstract}
Isolated left atrial appendage ostial stenosis has been previously described. The clinical implications of this anomaly are uncertain. The relative stasis behind ostial stenosis may result in systemic embolization, particularly stroke. We report the case of a 55 years old woman who has left atrial appendage ostial stenosis. She was admitted for radiofrequency catheter ablation of atrial flutter. We present this case to discuss whether life-long anticoagulation would be necessary for stroke prevention after successful radiofrequency catheter ablation

Keywords: Left atrial appendage ostial stenosis; Transesophageal echocardiogram; Anticoagulation; Stroke prevention

Abbreviations: AFL: Atrial Flutter; AF: Atrial Fibrillation; LVOT: Left Ventricular Outflow Tract; RFCA: Radiofrequency Catheter Ablation; TEE:

Transesophageal Echocardiogram; LAA: Left Atrial Appendage
\end{abstract}

\section{Introduction}

Left atrial appendage ostial stenosis with or without previous surgical- or catheter-based intervention has been previously described [1-5]. The clinical implications of this anomaly are uncertain because it's a very rare condition given the small number of cases reported. Herein, we report a case of left atrial appendage ostial stenosis with typical atrial flutter (AFL) and asymmetric septal hypertrophy.

\section{Case Report}

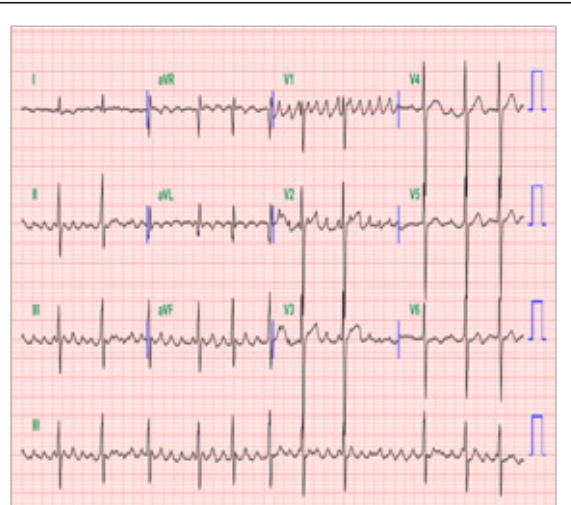

Figure 1: Baseline electrocardiography show typical atrial flutter
A 55-year old female was admitted to our hospital for radiofrequency catheter ablation (RFCA). She presented with severe palpitations and shortness of breath for 6 years and was diagnosed with typical AFL (Figure 1) she had been taking anti Arrhythmic agents, but tachycardia was not responsive antiarrhythmic drugs. She was recommended RFCA. A transthoracic echocardiography revealed a normal ejection fraction, asymmetric septal hypertrophy without LVOT obstruction (septum $=23.9 \mathrm{~mm}$, posterior wall $=7.6 \mathrm{~mm}$ ), and a dilated left atrium $(46 \mathrm{~mm})$. As part of evaluation before RFCA, a transesophageal echocardiogram was performed and revealed normal systolic function and asymmetric septal hypertrophy. The left atrial appendage was normal sized without thrombus or spontaneous echocardiographic contrast. There appeared to be a thin membranous structure at the orifice of the left atrial appendage with $0.3 \mathrm{~cm}$ sized central hole (Figure 2). This membranous structure was attached to the left atrial appendage wall at its base. Color Doppler showed flow acceleration across the hole (Figure 3). At Continuous-wave Doppler echocardiography across the hole revealed a peak velocity of $1.7 \mathrm{~m} / \mathrm{sec}$ during systole and atrial contraction in each direction (Figure 4). 


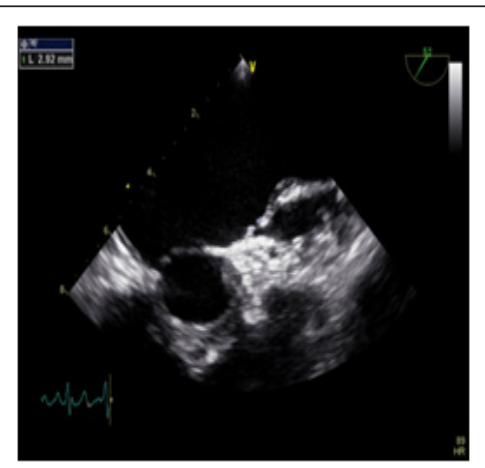

Figure 2: 2 dimensional transoesophageal echo cardiography of the left atrium and left atrial appendage demonstrating the stenosis at ostium of left atrial appendage.

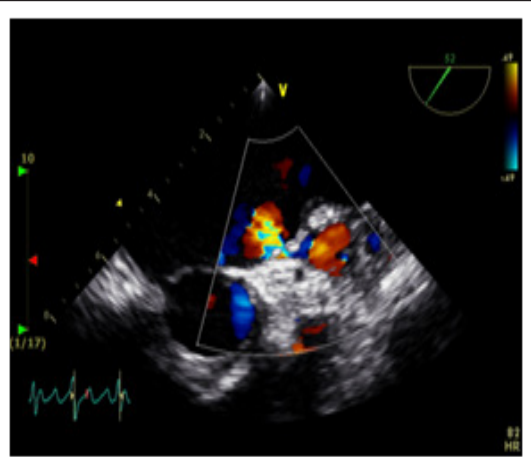

Figure 3: Color Doppler imaging revealed a high-velocity jet originating in the left atrial appendage and directed towards the body of the left atrium.

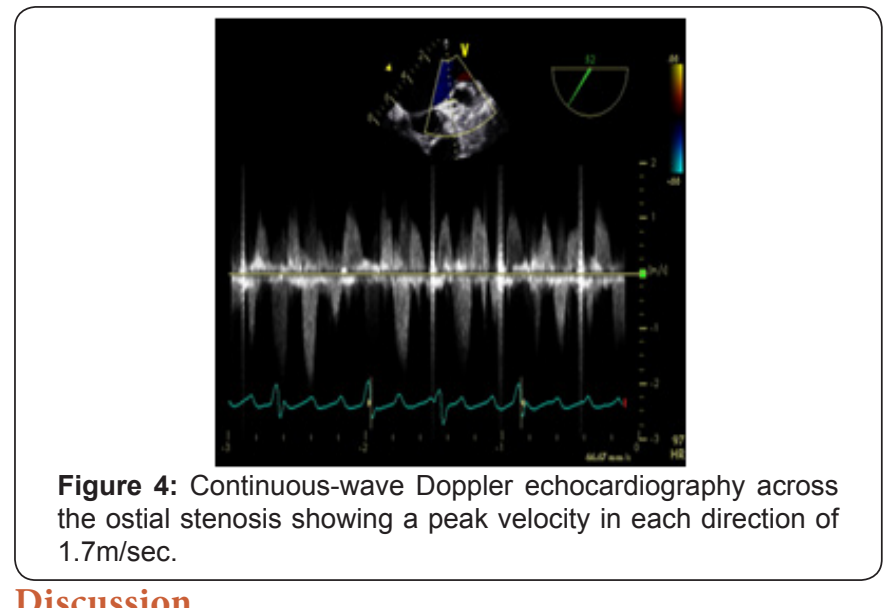

\section{Discussion}

Left atrial appendage ostial stenosis is a known complication in the postcardiac surgery setting that was probably associated with previous partially ligated left atrial appendage [1-2]. Isolated left atrial appendage ostial stenosis without previous surgical- or catheter-based intervention has been also previously described [3-5]. They explained that this anomaly represents a congenital defect, possibly a variant form of cor triatriatum, in which a membranous shelf divides the left atrium above the atrial appendage into 2 chambers. These previous reported 3 cases were patients in normal sinus rhythm ( 2 cases) and atrial tachycardia (1 case) without structural abnormality except left atrial appendage ostial stenosis.

In this case, the patient had no previous surgery or intervention involving the left atrium or appendage. Several reasons made this case unique. Unlike previous cases, a baseline rhythm of this patient was atrial flutter, in which chronic oral anticoagulation is recommended. Furthermore, we could not evaluate the remnant embolic risk because we performed RFCA and the patient's rhythm was recovered to normal sinus rhythm. And also, unlike previous cases with normal structure except left atrial appendage ostial stenosis, this patient had asymmetric septal hypertrophy.

Left atrial appendage ostial stenosis is a rare clinical entity. The clinical implications of this anomaly are uncertain given the small number of cases reported. The relative stasis behind ostial stenosis may lead to an increased likelihood of clot formation, or high-velocity jet across the stenotic orifice may strike the wall of the left atrium causing fibrosis and thrombus formation, resulting in systemic embolization, particularly stroke. Furthermore, systemic embolization is a major cause of death and disability in patients with atrial fibrillation and flutter. The LA, and specifically the left atrial appendage (LAA), is the most common location for atrial thrombus formation in the setting of atrial fibrillation or atrial flutter [6-8].

After RFCA, for patients without evidence of recurrent AF/ AFL and whose risk for embolization is low, anticoagulation is usually stopped. However, this structural anomaly may cause clot formation, it was difficult to stop the anticoagulation after RFCA in this case.

\section{References}

1. Katz ES, Kronzon I (1992) Incomplete ligation of the left atrial appendage: diagnosis by transesophageal echocardiography. Am J Noninvas Cardiol 6: 262-263.

2. Fisher DC, Tunick PA, Kronzon I (1998) Large gradient across a partially ligated left atrial appendage. J Am Soc Echocardiogr 11(12): 1163-1165.

3. Ha JW, Chung N, Hong YS, Cho BK (2001) Left atrial appendage stenosis. Echocardiography 18: 295-297.

4. Coughlan B, Lang RM, Spencer KT (1999) Left atrial appendage stenosis. J Am Soc Echocardiogr 12(10): 882-883.

5. Joshua D, Adam H, Robin S (2009) Isolated left atrial appendage ostial stenosis. European Journal of Echocardiography 10(5): 702-703.

6. Leung DY, Davidson PM, Cranney GB, Walsh WF (1997) Thromboembolic risks of left atrial thrombus detected by transesophageal echocardiogram. Am J Cardiol 79(5): 626-629.

7. Omran H, Rang B, Schmidt H, Illien S, Schimpf R, et al. (2000) Incidence of left atrial thrombi in patients in sinus rhythm and with a recent neurologic deficit. Am Heart J 140(4): 658-662.

8. Stoddard MF, Dawkins PR, Prince CR, Ammash NM (1995) Left atrial appendage thrombus is not uncommon in patients with acute atrial fibrillation and a recent embolic event: a transesophageal echocardiographic study. J Am Coll Cardiol 25(2): 452-459. 
This work is licensed under Creative Commons Attribution 4.0 License

DOI: $10.19080 /$ JOCCT.2017.07.555721
Your next submission with Juniper Publishers will reach you the below assets

- Quality Editorial service

- Swift Peer Review

- Reprints availability

- E-prints Service

- Manuscript Podcast for convenient understanding

- Global attainment for your research

- Manuscript accessibility in different formats ( Pdf, E-pub, Full Text, Audio)

- Unceasing customer service

Track the below URL for one-step submission https://juniperpublishers.com/online-submission.php 